\title{
Apreciaciones sobre el último discurso de Evita
}

Insights on Evita's last speech

\author{
Ailén Díaz ${ }^{1}$ \\ Universidad Nacional de La Plata - Argentina
}

Revista Derechos en Acción ISSN 2525-1678/

e-ISSN 2525-1686 Año 5/№ 16 Invierno 2020 (21 junio a 20 septiembre), 901-907

DOI: https://doi.org/10.24215/25251678e448

Aprobado: 15/09/2020

El 1 de mayo de 1952, Eva Perón reaparece en la escena pública, y dará su último discurso en el tradicional balcón de la Casa Rosada, ante una multitud, que se aglomeraba para celebrar en Plaza de Mayo el Día del Trabajador. A la mañana había sido recibida con gran ovación en el Congreso, antes que Perón inaugurara el $86^{\circ}$ Período Legislativo. Esta aparición pública, será la anteúltima de la primera dama, siendo la última vez, en compañía de Perón, un mes después de este memorable discurso, el 4 de junio al inicio de su segunda presidencia.

Para ese entonces, Evita estaba muriendo por un cáncer fulminante. Sin embargo, su temperamento seguía enérgico y con la misma pasión de siempre, pese a la debilidad de su cuerpo, prometió salir a las calles, si es que alguien se atrevía a derrocar al entonces presidente Juan Perón, "Yo le pido a Dios que no permita a esos insectos levantar la mano contra Perón, porque

\footnotetext{
Abogada, docente de la materia Historia Constitucional de la Facultad de Ciencias Jurídicas y Sociales de la Universidad Nacional de La Plata. (ORCID: https://orcid.org/00000001-8438-6622).
} 
iguay de ese día! Ese dí, mi general, yo saldré con el pueblo trabajador, yo saldré con las mujeres del pueblo, yo saldré con los descamisados de la patria para no dejar en pie ningún ladrillo que no sea peronista".

¿Por qué esa advertencia? Pues bien, eran tiempos políticos turbulentos. Hacía unos meses, había tenido lugar el primer intento de golpe de Estado contra el peronismo, el 28 de septiembre de 1951. Desde Campo de Mayo se había gestado - sin éxito - un levantamiento en armas de un grupo de militares de las tres fuerzas encabezado por el General Benjamín Menéndez. Hubo otro intento al poco tiempo, dirigida por el ex coronel José F. Suárez, tenía entre sus planes asaltar a la residencia presidencial y matar a Perón y a su esposa. Este intento fue realizado el 3 de febrero de 1952, pero las autoridades fueron alertadas antes de que se pueda poner en marcha el plan y los implicados en el hecho fueron detenidos. Así lo referenciará Evita “... no lo conseguirán... no lo conseguirán como no ban conseguido jamás la envidia de los sapos acallar el canto de los ruiseñores ni la víboras contener el vuelo de los cóndores...". Este mensaje era dirigido a los golpistas en particular, pero incluía a los opositores en general.

En ese contexto, se dieron las elecciones presidenciales que permitieron la reelección de Perón, el 11 de noviembre 1951, día histórico por consagrarse por primera vez el sufragio femenino, gracias a la Ley $\mathrm{N}^{\circ} 13.010$, impulsada fervientemente por Evita, quien pudo votar por primera vez en la cama del hospital.

No hacía mucho tiempo, había renunciado a su candidatura a la Vicepresidencia de la Nación, el 22 de agosto de 1951 a pesar de que una gran parte del Movimiento Nacional Justicialista se lo estaba pidiendo (en particular nos referimos al Partido Peronista Femenino y la Confederación General del Trabajo), las internas, en particular de los militares y su salud no la acompañaban.

Para mayo de 1952 la enfermedad estaba muy avanzada, pero ella no quería dejar de ver e interpelar a sus "descamisados", 
calificativo afectuoso con que caracterizaba al pueblo trabajador. Es así que durante el mensaje que estamos comentando, la "abanderada de los humildes" intentaba concientizar sobre los tiempos que corrían. De forma categórica le otorga un fuerte respaldo a su marido, el General Perón resaltando que "aquí estamos los hombres y las mujeres del pueblo, mi general, para custodiar vuestros sueños y para vigilar vuestra vida, porque es la vida de la patria, porque es la vida de las futuras generaciones, que no nos perdonarían jamás que no bubiéramos cuidado a un hombre de los quilates del general Perón, que acunó los sueños de todos los argentinos, en especial del pueblo trabajador". Asimismo, resaltó la necesidad de continuar sosteniendo el proyecto justicialista ya que todavía había "mucho dolor por mitigar; hay que restañar muchas heridas, porque todavia hay muchos enfermos y muchos que sufren".

Enardecida también advierte a los traidores de adentro y de afuera que el pueblo no se dejará "aplastar por la bota oligárquica y traidora de los vendepatria que han explotado a la clase trabajadora".

Con ímpetu pocas veces visto en una persona tras semejante lucha contra la enfermedad, Evita le reafirma al pueblo hacia el final de su discurso que "otra vez estoy en la lucha, otra vez estoy con ustedes, como ayer, como boy y como mañana", en una muestra de fortaleza frente a los tiempos políticos que se avecinaban.

Esta figura política femenina de Argentina, desató pasiones y odios. Tanta devoción generó por su acción a favor de los humildes, principalmente a través de la fundación con su propio nombre, que más de veinte mil firmas pidieron su beatificación ante la Iglesia Católica, incluso el pedido ha sido reiterado en el año 2019 por la CGT (Confederación General de Trabajo, la mayor Central Obrera Argentina).

No obstante, también despertó gran desprecio por otra parte de la sociedad más acomodada, que veían con malos ojos que una provinciana humilde llegase a casarse con un militar 
y candidato presidente de la Nación en aquel entonces, y que luego procuró dignificar a los desposeídos. Tanto fue el odio por la pérdida de ciertos privilegios por parte de dicha clase, que en barrios como Recoleta se vieron inscripciones en las paredes con la leyenda "viva el cáncer".

Lo que nadie podrá negar sin embargo, es su trascendencia en la historia de nuestro país, una de las mujeres más icónicas e influyentes de la Argentina. Falleció a causa del cáncer el 26 de julio de 1952, con tan solo 33 años, y pese a su corta vida dejó un legado inigualable, una muestra de pasión y amor por la dedicación al pueblo y la patria, y la férrea lucha contra quienes, nacionales o extranjeros, los oprimían, y lamentablemente aún oprimen.

\section{Eva Duarte. Discurso del $1^{\circ}$ de mayo de 1952}

Mis descamisados: otra vez estamos aquí reunidos los trabajadores del pueblo, las mujeres del pueblo, otra vez estamos los descamisados del pueblo en esta plaza histórica del 17 de octubre de 1945, para dar la respuesta al líder del pueblo que esta mañana, al concluir su mensaje, dijo que "quienes quieran oír, que oigan; quienes quieran seguir, que sigan". Aquí esta la respuesta mi general.

Es el pueblo...es el pueblo trabajador, es el pueblo humilde de la patria que aquí y en todo el país esta de pie y lo seguirá a Perón, al líder del pueblo y al líder de la humanidad, porque ha levantado la bandera de la rendención y de justicia de las masas trabajadoras, lo seguirá contra la opresión de los traidores de adentro y de afuera, y que en la oscuridad de la noche quieren dejar el veneno de sus víboras en el alma, y en el cuerpo de Perón, que es el ama y el cuerpo de la patria, no lo conseguirán, no lo conseguirán como no han conseguido jamás la envidia de los sapos acallar el canto de los ruiseñores, ni las víboras contener el vuelo de los cóndores. No lo conseguirán, porque aquí estamos los hombres y las mujeres del pueblo, mi General, para 
custodiar vuestros sueños y para vigilar nuestra vida, porque es la vida de la patria, porque es la vida de las futuras generaciones, que no nos perdonarán jamás que no hubiéramos cuidado a un hombre de los quilates de Perón, que acuñó los sueños de los argentinos, dignificando al pueblo trabajador.

Yo le pido a Dios que no permita a esos insectos levantar la mano contra Perón, porque iguay de ese día! Ese día, mi general, yo saldré con el pueblo trabajador, yo saldré con las mujeres del pueblo, yo saldré con los descamisados de la patria, para no dejar en pie ningún ladrillo que no sea peronista. Porque nosotros no nos vamos a dejar aplastar jamás por la bota oligárquica y traidora de los vende patrias que han explotado a la clase trabajadora, porque nosotros no nos vamos a dejar explotar jamás por los que, vendidos por cuatro monedas, sirven a sus amos de las metrópolis extranjeras; entregan al pueblo de su patria con la misma tranquilidad con que han vendido el país y sus conciencias; porque nosotros vamos a cuidar de Perón más que si fuera nuestra vida, porque nosotros cuidamos una causa que es la causa de la patria, es la causa del pueblo, es la causa de los ideales que hemos tenido en nuestros corazones durante tantos años. Hoy, gracias a Perón, estamos de pie virilmente. Los hombres se sienten más hombres, y las mujeres nos sentimos más dignas, porque dentro de la debilidad de algunos y de la fortaleza de otros está el espíritu y el corazón de los argentinos para servir de escudo en defensa de la vida de Perón.

Yo, después de un largo tiempo que no tomo contacto con el pueblo como hoy, quiero decir estas cosas a mis descamisados, a los humildes que llevo tan dentro de mi corazón que en las horas felices, en las horas de dolor y en las horas inciertas siempre levanté la vista a ellos, porque ellos son puros y por ser puros ven con los ojos del alma y saben apreciar las cosas extraordinarias como el general Perón. Yo quiero hablar hoy, a pesar de que el general me pide que sea breve, porque quiero que mi pueblo sepa que estamos dispuestos a morir por Perón y que sepan los traidores que ya no vendremos aquí a decirle 
"presente" a Perón, como el 28 de septiembre, sino que iremos a hacer justicia por nuestras propias manos.

Hay mucho dolor que mitigar; hay que restañar muchas heridas, porque todavía hay muchos enfermos y muchos que sufren. Lo necesitamos, mi general, como el aire, como el sol, como la vida misma. Lo necesitamos por nuestros hijos y por el país en estos momentos inciertos de la humanidad en que los hombres se debaten entre dos imperialismos; el de derecha y el de izquierda, que nos llevan hacia la muerte y la destrucción. Y nosotros, un puñado de argentinos, luchamos junto con Perón por una humanidad feliz dentro de la justicia, dentro de la dignificación de ese pueblo, porque en eso reside la grandeza de Perón. No hay grandeza de la Patria a base del dolor del pueblo, sino a base de la felicidad del pueblo trabajador.

Compañeras, compañeros: Otra vez estoy en la lucha, otra vez estoy con ustedes, como ayer, como hoy y como mañana. Estoy con ustedes para ser un arco iris de amor entre el pueblo y Perón; estoy con ustedes para ser ese puente de amor y de felicidad que siempre he tratado de ser entre ustedes y el líder de los trabajadores.

Estoy otra vez con ustedes, como amiga y como hermana y he de trabajar noche y día por hacer felices a los descamisados, porque sé que cumplo así con la Patria y con Perón. He de estar noche y día trabajando por mitigar dolores y restañar heridas, porque sé que cumplo con esta legión de argentinos que está labrando una página brillante en la historia de la Patria. Y así como este $1^{\circ}$ de mayo glorioso, mi general, quisiéramos venir muchos y muchos años y, dentro de muchos siglos, que vengan las futuras generaciones para decirle en el bronce de su vida o en la vida de su bronce, que estamos presentes, mi general, con usted.

Antes de terminar, compañeros, quiero darles un mensaje: que estén alertas. El enemigo acecha. No perdona jamás que un argentino, que un hombre de bien, el general Perón, esté trabajando por el bienestar de su pueblo y por la grandeza 
de la Patria. Los vende patrias de dentro, que se venden por cuatro monedas, están también en acecho para dar el golpe en cualquier momento. Pero nosotros somos el pueblo y yo sé que estando el pueblo alerta somos invencibles porque somos la patria misma. 